\title{
Environmental Justice, capabilities, and the theorization of well-being
}

Gareth A. S. Edwards, School of International Development, University of East Anglia, gareth.edwards@uea.ac.uk

Louise Reid, Department of Geography \& Sustainable Development, University of St Andrews,lar9@st-andrews.ac.uk

Colin Hunter, Department of Geography \& Sustainable Development, University of St Andrews,ch69@st-andrews.ac.uk

\section{$\underline{\text { Abstract }}$}

Environmental Justice (EJ) scholarship is increasingly framing justice in terms of capabilities. This paper argues that capabilities is fundamentally about well-being, and as such there is a need to more explicitly theorize well-being. We explore how capabilities have come to be influential in EJ and how well-being has been approached so far in EJ specifically and human geography more broadly. We then introduce a body of literature from social psychology which has grappled theoretically with questions about well-being, using the insights we gain from it to reflect on some possible trajectories and challenges for EJ as it engages with well-being.

\section{$\underline{\text { Keywords }}$}

environmental justice, well-being, capabilities, justice, environmental ethics, eudaimonia, hedonia 


\section{Introduction}

The roots of Environmental Justice (EJ) scholarship are inherently geographical, and can be traced to activists and scholar-advocates in the USA concerned about the co-location of noxious environmental facilities such as landfills, hazardous waste facilities and 'dirty' industry with poor, black communities (Bullard, 1990; Cutter, 1995; Di Chiro, 1996). It has, as Walker (2009b) aptly observed, always worn its normative heart on its sleeve, and so as the literature matured, it is unsurprising that it attracted criticism from both within and without for adopting liberal, distributive notions of justice rather too easily (Swyngedouw and Heynen, 2003) and for being insufficiently self-reflexive in its approach to justice and injustice (Schlosberg, 2004; Walker and Bulkeley, 2006; Walker, 2009b). But if this were true of the early literature - the purpose of which was to highlight some manifestly unjust specific situations mostly affecting communities of colour in the USA - it certainly is not of more recent interventions. EJ is identified by Barnett (2011: 247) as one of "the two areas of debate in geography where the concept of 'justice' is most seriously at stake" (the other being work on 'right to the city')

The first steps to a more robust theorization of justice within EJ were taken by David Schlosberg, who argued based on his analysis of EJ movement demands that justice must be understood as multivalent (Schlosberg, 2004). Subsequently, a number of scholars have been pushing the boundaries of theorizing what justice means, drawing on recent shifts in political philosophy which have emphasized the non-distributive dimensions of justice (Young, 1990; Sen and Nussbaum, 1993; Fraser, 1997; Fraser, 2000; Honneth, 2004; Sen, 2009). In particular, a small but critical group of scholars have begun to advocate the 'capabilities approach' to justice as a conceptual scaffolding within which to theorize EJ (Holland, 2008; Walker, 2009b; Walker, 2012; Whitehead, 2009; Schlosberg and Carruthers, 2010; Schlosberg, 2012; Forsyth, 2014; Schlosberg, 2007). Developed predominantly by Amartya Sen and Martha Nussbaum, the capabilities approach seeks to provide an alternative way to understand justice to the Rawlsian paradigm of 'justice as fairness' which has dominated Anglophone political philosophy since the publication of $A$ Theory of Justice in 1971 (Sen and Nussbaum, 1993; Nussbaum, 2006; Sen, 2009; Rawls, 1999). The central argument is that justice is not about achieving an appropriate distribution of things between people (Rawls' 'primary goods'), but rather about people being able to live lives that they consider worthwhile (Sen and Nussbaum, 1993).

There is much to like about the capabilities approach, particularly from an EJ perspective, notwithstanding the critiques it has attracted in the philosophical literature (e.g. Jaggar, 2006; Arneson, 2013). But one of its central characteristics is that it explicitly defines justice in terms of the related concept of 'well-being'. Well-being is not frequently subjected to sustained conceptual scrutiny either by EJ scholars or human geographers more broadly. Nor has it, so far, attracted much attention from the broader EJ movement, which has focussed its attention on highlighting and campaigning against the distributive, participatory and (increasingly) cultural manifestations of injustice (Sze and London, 2008). Of course, these are natural and very valid fronts to focus on, and in the course of 30 years significant progress has been made on them. But even notwithstanding the increasing tendency to frame justice in terms of capabilities, well-being is clearly an important undercurrent driving EJ praxis. It is the well-being of disadvantaged people 
and communities relative to their advantaged peers which forms the grist in the struggle for environmental justice that the movement organizes around.

So we think the literature has reached a point where it is time to bring well-being more squarely into focus and subject it to some critical scrutiny. We think this is of particular importance in working through the implications of the recent shift towards framing the 'justice' of EJ in terms of capabilities theory. While this paper is focussed predominantly on debates within EJ, it should also be of broader interests to geographers whose work interfaces with questions of well-being, including those working on justice, health, affect and emotion (for a recent themed issue on this, see Schwanen and Atkinson, 2015). In the rest of the paper, then, we argue that capabilities is fundamentally about well-being (Section II); explore how capabilities have come to be influential in EJ (Section III) and how well-being has been approached so far in EJ specifically and human geography more broadly (Section IV); introduce a body of literature from social psychology which has grappled theoretically with questions about well-being (Section V); and, finally, consider some potential future trajectories and research needs.

\section{Capabilities and well-being}

In the early 1990s Amartya Sen and Martha Nussbaum began questioning whether any transcendental theory in the social contract tradition was either theoretically adequate or (more importantly) politically relevant (see Sen and Nussbaum, 1993). Of course, the towering theory in this tradition was - and remains-Rawls' A Theory of Justice, on which both focussed their critical attention. Rawls had set out his theory of justice as an alternative to classical utilitarianism, and deliberately constructed it in transcendental terms, seeking to understand "the principles of justice that would regulate a well-ordered society. Everyone is presumed to act justly and to do his part in upholding just institutions" (Rawls, 1999: 8). Sen argued that theories such as Rawls" may be "marvellously radical", but nevertheless "would not be much invoked in the actual debates on justice in which we are engaged" (Sen, 2009: 100). Nussbaum "singled out Rawls's theory for critical examination because it is the strongest political theory in the social contract tradition that we have" (Nussbaum, 2006: ix), and argued that Rawls and the social contract tradition had failed to provide illumination on debates including women's equality, transnational justice, and inter-species justice (Nussbaum, 2006). The capabilities-based approaches of both Sen and Nussbaum (collectively: 'capabilities theory') emerged as a critique of the social contract tradition in western political philosophy, an alternative approach to justice which both argued was of more utility in explaining the world we live in and providing guidance for how to live better in it. Capabilities theory is a direct challenge to the entire social contract tradition of philosophy, because rather than viewing justice as absolute it instead argues that justice is comparative - it depends on what people value. In practice, this means that capabilities theory sees well-being, rather than the distribution of goods, as the ultimate measure of justice. Sen himself explained it as "a particular approach to well-being and advantage in terms of a person's ability to do valuable acts or reach valuable states of being" (Sen, 1993: 30). Justice is considered to be achieved when people are able to live lives that they consider to have value. 
Subsequently, Sen and Nussbaum have diverged in how they assess this value: Nussbaum towards an Aristotelian objective-list account which suggests a finite number of relevant human functionings that must be considered (though she has subsequently retreated from this position see Arneson, 2013), and Sen towards a less prescriptive account of capabilities in which "individual advantage is judged ... by a person's capability to do things he or she has reason to value" (Sen, 2009: 231). Sen tends to see 'freedom' rather than 'well-being' as the central criterion for justice within the capabilities approach, as it accommodates the notion that people validly value things other than their own well-being alone. However, as Arneson (2013: 195) argues in his critique of Sen's The Idea of Justice,

Much the same is true of freedom and capability. They are of supreme importance, but they do not provide reasons for action and policy that stand independent of well-being concerns. Capabilities are crucial means to wellbeing and some aspects of freedom and capability are partly constitutive of important components of well-being. That gives capability its due.

In other words, a good case can be made for well-being as the ultimate value in the capabilities approach, and the implication of this is that any use of the capabilities approach must necessarily be cognisant of broader debates about well-being. In particular, since capabilities theory focusses almost exclusively on individuals as morally-relevant subjects, there seems to be a case for examining work proceeding largely from social psychology on the question of personal (or psychological) well-being, in order to deepen and broaden the understanding of and engagement with the underlying concept of well-being. However, before we introduce this literature, it is important to understand how capabilities theory has emerged in EJ, and also how well-being is already being treated in EJ. We turn to these questions in the next two sections.

\section{Environmental Justice, justice pluralism, and capabilities}

In the 1980s, activists in the American South began to organise around the growing realisation that environmental 'bads' such as toxic waste dumps and dirty industry were overwhelmingly colocated with black communities, particularly poor ones (Bullard, 1990). If the initial concern was of 'environmental racism', it quickly developed into a broader movement for 'environmental justice' building on the achievements of the civil rights movement in particular, as well as elements of the environmental movement. EJ was first and foremost an activist concern, but quickly developed into a broader political and scholarly project (Cutter, 1995; Debbané and Keil, 2004; Walker, 2009a). As it grew, the justice concerns of actors working under an EJ 'umbrella' have diversified greatly; from the disproportionate ability of elites to shape the global economy through institutions such as the World Trade Organization to the right of indigenous and local communities to be recognised as valid interests in land-use discussions in both developed and developing countries in addition to context-specific demands over environmental quality (Schlosberg, 2004; also Agyeman et al., 2003). Perhaps for this reason, the EJ movement has never sought to develop a unifying narrative on justice, and EJ scholarship has largely followed suit. Rather than seeing the 'militant particularism' of the EJ movement as a weakness (as David Harvey does, see Harvey, 1996), EJ scholars have constructed the necessary theoretical supports 
for understanding justice as multivalent and pluralistic, recognising diversity without attempting to homogenise it.

David Schlosberg's work has been influential in this regard. He argued that justice should be understood as 'trivalent', requiring attention to issues of distribution, participation and recognition as "three interlinking, overlapping circles of concern" (Schlosberg, 2004: 521; also Schlosberg, 2007). If distribution and participation can be mapped onto traditional, liberal justice concerns, the notion of recognition is derived from work in left-wing and feminist political philosophy which has questioned the primacy of distribution in the justice calculus (Fraser, 1997; Honneth, 2004). This trivalent understanding of justice has subsequently been widely adopted in the literature, which has been characterised in recent years by a commitment to 'justice pluralism' (Walker and Bulkeley, 2006; Holifield et al., 2009; Walker, 2012; Martin, 2013). The engagement with the 'capabilities approach' to justice has emerged as scholars have developed this engagement. In Defining Environmental Justice (2007), Schlosberg introduced EJ scholars to capabilities theory, arguing that capabilities could be understood as an additional dimension of justice and that capabilities theory could also be a more productive theoretical edifice within which to theorize EJ than the contractarian, liberal egalitarian 'justice as fairness' approach associated with Rawls. In this sense, the turn to capabilities was in part a response to claims from some critics that EJ had lost its radical edge. Swyngedouw and Heynen (2003), for instance, argued in making their case for the merits of Urban Political Ecology over EJ that "the environmental justice movement speaks fundamentally to a liberal and, hence, distributional perspective on justice, in which justice is seen as Rawlsian fairness and associated with the allocation dynamics of environmental externalities" (Swyngedouw and Heynen, 2003: 910). This argument resonated with critiques even from within the EJ tradition. For instance Gordon Walker observed that geographical EJ scholarship "has been largely bereft of sustained reasoning about what the justice in environmental justice should constitute and why" (Walker, 2009b: 205), and Ryan Holifield showed how the Clinton administration deployed neo-communitarian strategies in an (ultimately, in his view, unsuccessful) attempt to make "the idea of environmental justice, usually invoked as a challenge to market-driven environmental policy, compatible with processes of neoliberalization" (Holifield, 2004: 287).

For Schlosberg, Walker and a growing list of others, capabilities theory supports the core beliefs and radical heart of EJ praxis, while adding nuance and sophistication to the theorization of justice, most notably providing theoretical support for the idea and practice of justice pluralism (Schlosberg, 2007; Schlosberg, 2012; Schlosberg, 2013; Walker, 2009b; Walker, 2012; Schlosberg and Carruthers, 2010; Martin, 2013; Holland, 2014). Walker explains why it is a good fit for EJ: "it has an internal pluralism, incorporates a diversity of necessary forms of justice, rather than privileging only one, and retains flexibility in how functionings and flourishings are to be secured" (Walker, 2009b: 205). Indeed, with some minor adjustments - such as the admonition that Sen's rather individualistic application of capabilities should be "extended to include collective or community functioning" (Walker, 2009b: 204; following Schlosberg, 2007) — capabilities is rapidly becoming the core theoretical edifice within which to understand and theorize (environmental) justice. But given that well-being is the ultimate value in the 
capabilities approach, we argue that EJ scholars need to begin to pay much more direct and careful attention to their theorization of well-being, as well as their theorization of justice.

\section{Locating well-being within EJ}

Well-being, it must be conceded, is not prominent in the EJ literature, although preserving or improving the well-being of particular communities is the motive force behind much of the organizing conducted under an environmental justice umbrella (Mohai et al., 2009). If we are to draw up a rather crude schema to categorise the explicit mentions of well-being in the literature, two formulations emerge: as 'economic well-being', where it is broadly synonymous with what neoclassical economists call 'utility', and as an ancillary of health. In neither formulation is wellbeing really the object of analysis. Rather, it is an input to or an outcome of particular relationships and conditions, something quantifiable and measurable, something rather uncontroversial.

An example of the first formulation can be found in Haughton's attempt to assess the EJ implications of four different models of sustainable urban development. Haughton (1999: 234) argues that "Moving toward sustainable development requires economic and social systems that encourage environmental stewardship of resources for the long term, acknowledging the interdependency of social justice, economic well-being, and environmental stewardship". Here, well-being is something analytically distinct from social justice, though Haughton advocates its interdependency with both justice and environmental concern. But most of the time, the absence of any specific mention of well-being has the effect of silently legitimizing the preference-based accounts so prominent in mainstream economic thinking. Indeed, Sagoff (2008) takes the whole discipline of environmental and neoclassical welfare economics to task for assuming that wellbeing can be expressed as a function of willingness-to-pay, with the effect that preferencesatisfaction can be used as a proxy for it. Dodds (1997), likewise argues for a more expansive understanding of well-being than that generally adopted by environmental economists, and a host of more recent interventions have taken issue with it in both philosophical and practical terms (e.g. Ferraro and Reid, 2013; Bina and Vaz, 2011; Frey and Stutzer, 2005; Layard, 2005).

The second formulation binds well-being to health. For example, Albrecht (1995: 68) argues that the EJ movement "is leading many minority and lower-income citizens to demand a greater voice in decisions that affect their health and well-being", and Adger (2002: 1719) observes that "It is the poor who reside and work in places where unsustainability is bad for your health and wellbeing and who have little or no choice in their lifestyles". Indeed, the conflation of health and well-being is even detectable in recent work bringing together EJ and health geographies (Pearce et al., 2010). This is not surprising, in one sense. The origins of the moniker can be traced to the World Health Organization's 1948 definition of health as a 'state of ... wellbeing' rather than the 'absence of disease', which was an attempt to "reconceptualize health and health care practice away from a focus on the individual and absence of specific diseases towards seeing health as a positive attribute" (Fleuret and Atkinson, 2007: 106). However, as commentators both within health geography and social psychology have observed, in practice the 'health and well-being' moniker has successfully broadened the conceptualization of health but entirely failed to define 
well-being (Fleuret and Atkinson, 2007; Bourke and Geldens, 2007), despite wide usage in the medical humanities and health geography in the last 20 years. Moreover, bundling health and well-being together in such a fashion implies a direct relationship between health and well-being which is hard to sustain either in philosophical terms or in reality.

Thus, while well-being has always been an implicit concern of the EJ movement, EJ scholarship has not directly sought to theorize it. If the recent shift to capabilities within EJ reflected a 'theoretical turn' which sought to correct a rather uncritical and unproblematic approach to the 'justice' of EJ, a similar shift is needed in how scholars engage with the related notion of wellbeing. But this theorization is relatively under-developed at present, even amongst scholars working with capabilities theory. Explicit discussion of or reflection on well-being is not prominent in Schlosberg's early work, which has been particularly influential in charting out the applicability of the capabilities approach to EJ (Schlosberg, 2007; Schlosberg, 2013), despite the fact that Schlosberg and Carruthers (2010: 15) summarise the capabilities approach as being centrally concerned with "the justice of arrangements not simply in distributive terms, but more particularly in how those distributions affect the ultimate wellbeing and functioning of people's lives".

Other commentators have raised well-being more explicitly. Breena Holland recently argued that, at least in Nussbaum's approach, one of the most significant benefits of capabilities is the fact that they "provide a more accurate account of individual well-being than a person's goods and resources can illuminate" (Holland, 2014: 69), such that capabilities theory illuminates "the basic features of a theory of well-being that defines both what comprises well-being and why, thus conceived, it can improve well-being assessment as theorized and practiced in international development policy" (Holland, 2014: 69). Capabilities, in this sense, is an approach to defining well-being, and justice is to be found in the extent to which people are able to achieve this wellbeing. Gordon Walker's (2009b) brief intervention in Antipode, likewise, puts well-being in a central position in talking about the substance of capabilities, showing that for him capabilities are fundamentally about well-being. Walker finds "much potential in using the capabilities approach to structure normative thinking about environmental concerns ... While there are some (a few) core aspects of human well-being that surely do transcend place and time, there are others that will be specific and necessarily reflective..." (Walker, 2009b: 205, emphasis added). Subsequently, writing with Day, Walker argues that "the injustice of fuel poverty can be read as a lack of recognition of the needs of certain groups, and, more fundamentally, as a lack of equal respect accorded to their wellbeing" (Walker and Day, 2012: 71).

So scholars are somewhat inevitably being drawn into discussions about well-being as they seek to develop a capabilities-based EJ. But much more needs to be done in this regard, because as Ballet et al. (2013) acknowledge in an early attempt to defend a capabilities-based conception of EJ, “The capabilities approach is an attempt to renew the assessment of wellbeing, in a manner that can stand up to utilitarianism and resourcist approaches" (Ballet et al., 2013: 29). As it stands, however, well-being remains under-theorized in the EJ context, something which the capabilities approach seeks to give form to but which remains out of direct sight. Here there seem to be clear gains to be made from engaging with work, mainly from social psychology, which has 
sought to theorize and understand the psychological dimensions of personal well-being. We believe that engagement with this literature provides an entry-point into a theorization of wellbeing which would be productive for EJ scholars to explore. We turn to this literature in the next section.

\section{Theorizing well-being}

There is a significant body of literature, mainly within the social psychology tradition, which focusses on what it means to be well or unwell (Diener and Biswas-Diener, 2008; Mathews and Izquierdo, 2009), how these understandings of wellness relate to life experiences (Christopher, 1999), and how well-being can be measured (Linley et al., 2009). Where well-being is used without a qualifying prefix (as with the capabilities approach) it is generally some kind of personal or psychological well-being which is being discussed, but a wide variety of qualifiers are often brought into the discussion. For instance, we can consider well-being at specific times (such as childhood well-being) in specific locations (such as neighbourhood well-being) or for different groups of people, such as communities, societies and cultures (community well-being, social well-being and cultural well-being respectively). Well-being is a difficult concept to pin down. In this section, we introduce this literature, examine the dominant theorizations of wellbeing within it, and consider how they relate to the capabilities approach and EJ more broadly. We confine our discussion here to notions of personal - or what might better be called psychological-well-being, reflecting the key role that individual psychology has had in these debates. Such notions seem to us most directly relevant to the capabilities approach, but it is likely that EJ scholars would want to engage with related notions, particularly those centred on community, in addition, building on the work of Schlosberg (2007).

Much of the psychological well-being literature is - not surprisingly-dominated by social psychology, although the philosophical bases of the debates reach back as far as the ancient Greeks. Such literature has been divided fairly straightforwardly into two approaches to wellbeing. The first conceptualizes well-being in hedonic terms, arguing that well-being is about achieving a state of subjective personal happiness ${ }^{\mathrm{i}}$. It has tended to use the term 'subjective wellbeing' (Diener et al., 1999; Kesebir and Diener, 2008; Pavot and Diener, 1993; Tiberius, 2004), and we might draw some parallels between it and debates in EJ which have sought to explore the subjectivities and experiences of (in)justice. The second conceptualizes well-being in eudaimonic terms, arguing that well-being entails much more than simply feeling subjectively happy; that well-being is about achieving a satisfaction with one's life whether or not one feels subjectively happy (Huta and Ryan, 2009; Ryan and Deci, 2001; Ryff and Singer, 2008). Human geographers have also engaged with discussions of well-being, with recent articles on the 'geographies of well-being' (Schwanen and Atkinson, 2015; Atkinson, 2013) illustrating the contributions of geography in recognising the concept as subjective and relational (Andrews et al., 2014; Atkinson and Joyce, 2011; Kearns, 2014), related to ideas of emotion (Tucker, 2011). Whilst this is a growing body of scholarship, the distinction between philosophical traditions of hedonia and eudaimonia is not one that EJ scholars or human geographers more broadly have engaged with in a sustained way. 
The literature in the hedonic tradition focusses on understanding and examining how satisfied individuals are with particular elements of their lives, such as work, health and relationships. It understands well-being in terms of positive emotions and moods, or alternatively the absence of negative emotions and moods (Kesebir and Diener, 2008). Scholars working on subjective wellbeing have sought to measure well-being through proxies such as the extent to which individuals feel happy and satisfied in life, and then developed scales of well-being in an attempt to facilitate comparisons of relative psychological well-being between people (Diener et al., 2006). In developing such comparative instruments, there are parallels with the way the neoclassical economic tradition uses preference satisfaction as a proxy for well-being. But the work on psychological well-being adopts a much broader framing of the drivers of well-being, and articulates with broader work from philosophy which strongly rebuts the suggestion that preference satisfaction is a reliable proxy for even hedonic well-being. As O'Neill argues,

\footnotetext{
"Individuals' preferences are a reliable guide to hedonic well-being only if at least two conditions are met: first, personal hedonic well-being is the object of their preferences; second, they are able make reliable judgements about what will make them happy ... there are often good reasons to question the first condition. However, it is the second condition that has been principally questioned in recent hedonic research.” (O’Neill, 2008: 12)
}

Notwithstanding its internal debates, the hedonic approach to well-being has been criticised for assuming that there is one single pursuit of happiness (Mathews and Izquierdo, 2009), and that happiness should be maximised wherever and whenever possible (Fleuret and Atkinson, 2007). Furthermore, measures of hedonia have been criticised for being of limited scope as they only measure certain, limited aspects of life satisfaction (Mathews and Izquierdo, 2009). In this context, we turn our attention to the major competing approach to theorizing well-being: the eudaimonic approach.

Eudaimonia is a more encompassing concept than hedonia and understands well-being in terms of a person's ability to flourish, where flourishing encompasses elements such as success and virtuousness in addition to happiness. In terms of psychological well-being, the key distinction between hedonic and eudaimonic perspectives is that the former emphasises the absence of negative feelings or life events, whilst the latter does not. For eudaimonic theorists such as Ryan and Deci (2001), events that do not provide pleasure or contribute to an individual's (subjective) happiness may nonetheless allow the individual to flourish and thus contribute to their well-being. In essence, within the eudaimonic tradition, psychological well-being can exist through the achievement of goals that are not necessarily pleasure-giving, with happiness only ever one part of what makes individuals feel 'well'. However, if there is debate in the hedonic tradition over what is required to ensure, and how to measure happiness, there is an even greater division amongst eudaimonic theorists. This division concerns the exact meaning and translation of 'eudaimonia', and in particular the psychological needs important for personal well-being and how it may be measured. The first is 'psychological well-being' (PWB), which was developed by Carol Ryff and colleagues and argues that there are motives underlying eudaimonic well-being, which can be measured across six dimensions; autonomy (a sense of self-determination); environmental mastery (capacity to manage one's life and surrounding world); positive relations 
with others; purpose in life (belief that one's life is purposeful and meaningful); personal growth (a sense of continued growth and development as a person); and self-acceptance (a positive evaluation of oneself and one's past life). The second is 'self-determination theory' (SDT) (Ryan and Deci, 2001), which argues that there are three basic needs: having the choice to do what one wants (autonomy); being effective and achieving valued outcomes (competence); and, to love and be loved (relatedness), and that the degree to which these are achieved impacts on well-being. PWB and SDT share an interest in establishing the degree to which an individual's behaviour is self-motivated and self-determined, and both use an objective list of factors to explain such phenomena. The critical difference between the two is that whereas SDT identifies the principal factors that create well-being, PWB identifies factors to define well-being.

Of course, the hedonic and eudaimonic approaches to well-being cannot be entirely divorced from each other, and though there are significant philosophical differences, scholars have increasingly come to understand that they are not necessarily mutually exclusive. For example, studies have shown that if individuals have positive feelings they are also more likely to report higher levels of meaning in life (Diener and Biswas-Diener, 2008). This suggests some interdependency between hedonic and eudaimonic 'forms' of psychological well-being which is yet to be fully understood but may have important repercussions for how well-being is theorized. Indeed, O'Neill $(2006 ; 2008)$ has argued for a rapprochement between the eudaimonic and hedonic approaches to well-being in the context of environmental thought, suggesting that eudaimonia is catholic enough to provide space for both approaches. Other studies have sought to quantify the difference between hedonia and eudaimonia at a variety of scales (including national and international studies, and within and across cultures), in an attempt to understand and explain the differences between those who report higher or lower levels of personal well-being (Fleuret and Atkinson, 2007). Typically, this body of research has examined relationships between wellbeing and other factors such as health, achievement, social relationships, religion, aging and personality. An example is the work of Ryff et al. (2004), which explored the extent to which eudaimonic and hedonic constructs and measures of well-being correlate with indicators of physical health.

One of the key challenges for scholars working on well-being has been the fact that a sense of well-being is highly specific to individuals, hard to causally relate to external conditions, and variable across the life span of people (Ryff et al., 2004). For instance, conditions such as physical health or housing quality may be poor, but a sense of well-being high (Fleuret and Atkinson, 2007). Likewise, there is considerable consensus that a person's sense of well-being changes across the life-course, with research suggesting a ' $U$ ' shaped temporality to peoples' sense of their own well-being, such that well-being reaches a minimum in middle age (mid to late 40s), regardless of generation (Blanchflower and Oswald, 2008). The hedonic tradition has been most susceptible to the criticism that it is indifferent to the future, which O'Neill argues is a significant weakness, because "The future determines what appraisal we can give to the present" (O'Neill, 2006: 165). In short, the complexity and diversity of interpretations of well-being poses significant challenges, even within the psychological tradition. In EJ scholarship, terms such as well-being, happiness, flourishing, capabilities and functionings all come up, often used 
interchangeably. But this 'loose' usage obscures ontological and epistemological differences including fundamental ones - and suggests that a much more direct and substantive engagement with the theoretical debates about the meaning and pursuit of well-being is required, particularly if capabilities is to provide the theoretical scaffolding within which the 'justice of EJ' is pursued and defined. In the next section, we attempt to begin this process by locating EJ relative to the hedonic and eudaimonic approaches to well-being and highlighting some potential traps as well as some opportunities raised by the increasing shift towards a capabilities approach to justice.

\section{Trajectories: What kind of well-being for what kind of EJ?}

A fundamental shift is taking place in how EJ scholars theorize justice, as a growing number argue for capabilities theory as a scaffolding within which to theorize justice. In this paper, we have argued that capabilities theory fundamentally defines justice in terms of well-being, but that the literature on psychological well-being highlights how contested well-being is. There might be substantial agreement that well-being is a good thing, but there is considerable and fundamental disagreement about what it means to 'be well', and whether well-being should be understood in hedonic terms as a matter of subjective happiness or in eudaimonic terms as a matter of broader satisfaction with life. Given this, there is a pressing need for scholars developing capabilitiesbased theorizations of justice ('capabilities EJ') to begin to devote at least as much attention to well-being as they do to justice. However, we would also contend that the well-being genie is out of the bottle for EJ more broadly.

In this concluding section, then, we seek to stimulate this debate by reflecting on some of the possible trajectories and challenges for EJ scholarship as it engages with well-being in a more sustained manner. Our focus in doing this is on the emerging 'capabilities EJ' since we think this represents the direction EJ engagements with justice are moving. This means contrasting capabilities EJ with 'traditional EJ' scholarship, which largely subscribed to a Rawlsian notion of justice. Given the acceptance within EJ of the notion of justice pluralism, suggesting that all precapabilities EJ was Rawlsian is a rather obvious simplification. However, the Rawlsian framing of justice was arguably the dominant one (Swyngedouw and Heynen, 2003; Walker, 2009a), and this simplification is analytically helpful to illuminate some key questions and issues which we think scholars will be forced to grapple with as they bring well-being more directly into debates about EJ. So we ask the reader to bear with us. To start this process, we have developed a simple schematic graph that we hope proves a useful tool to stimulate reflection and discussion about what kind of well-being EJ seeks and what kind of well-being the outcomes of EJ praxis might deliver (Figure 1). 


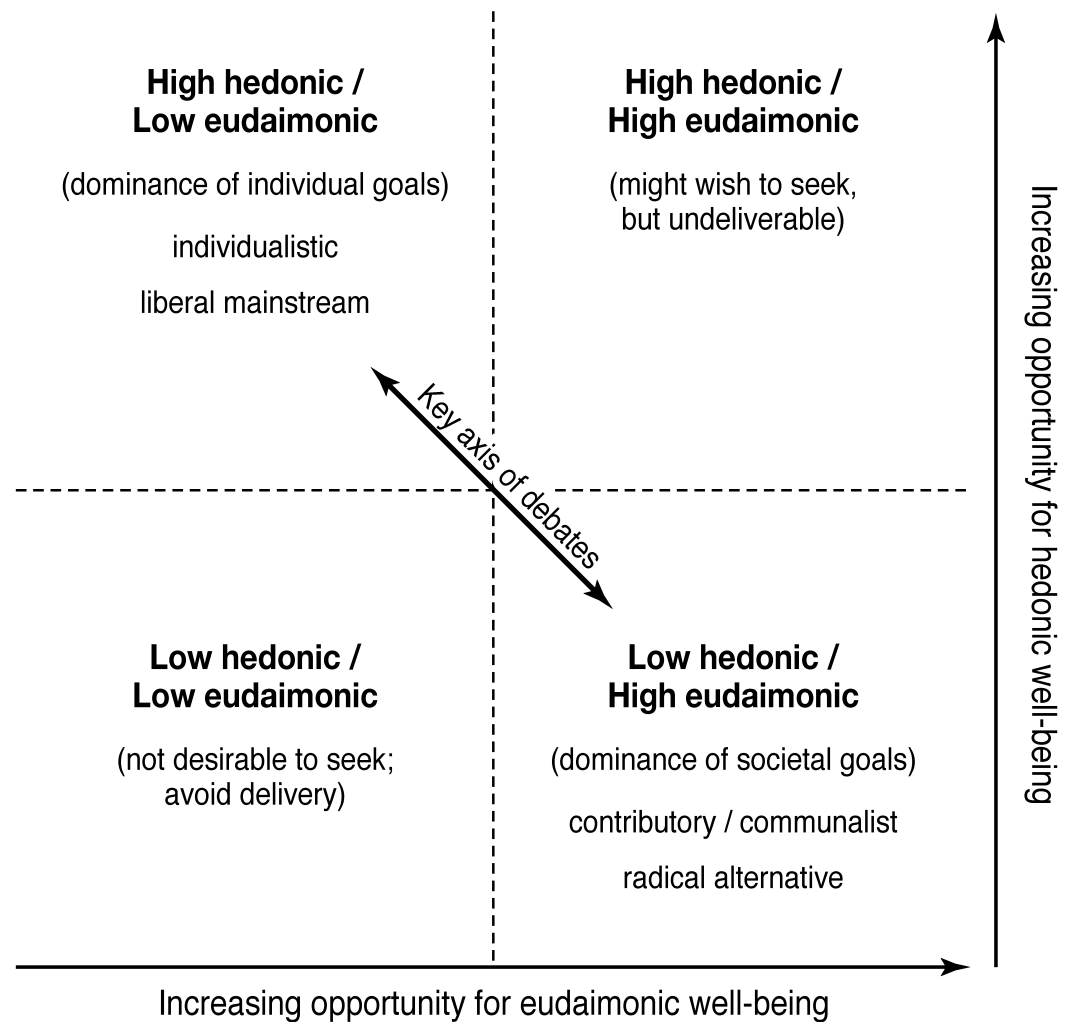

Figure 1: What kind of well-being for what kind of environmental justice?

Our starting point is that well-being of some form is a desired outcome of any theory of justice, and that — notwithstanding the complex relationship between them — eudaimonia and hedonia are the dominant theorizations of psychological well-being. So if the chart represents opportunity for well-being, for the purposes of analytical simplicity we can divide it into four quadrants. Having done this, our first observation is that the bottom left quadrant is a deleterious outcome: if justice delivers neither hedonic nor eudaimonic well-being, it is a very meagre form of justice, not much to be desired. The basis of this is the same argument against a strict intrinsic egalitarianism, and the common analogy is given of the blind person - if equality demands that those with sight are deprived of it, then such an egalitarian principle is not likely to attract much support. We might similarly exclude from further consideration the top right quadrant, which would be a form of justice which maximises opportunity for both hedonic and eudaimonic well-being. Though this would be a highly desirable state of affairs, given the theoretical tensions between hedonia and eudaimonia and our practical knowledge of the scale and extent of existing injustices, it is likely to be unachievable.

This leaves a choice for scholars and activists (ourselves included!) between pursuing a justice which maximises the opportunity for hedonic well-being and one which maximises opportunity for eudaimonic well-being, visually represented in our diagram as the 'axis of key debates'. Seeking to maximise hedonic well-being is consistent with a notion of justice which gives primacy to the individual and their goals, and thus with the individualistic orientation of 
contemporary liberal society. On the other hand, seeking to maximise eudaimonic well-being is consistent with a notion of justice which gives primacy to society and its collective goals. This is more contributory or communalist in orientation, and runs against the grain of contemporary society; it is more radical and alternative.

So what sort of well-being should EJ seek? Some scholars have recently argued that hedonic conceptions of well-being can be mobilized in support of pro-environmental action such as green consumerism (Soper, 2007), at least in part because "Hedonic research offers the possibility of decoupling growth in consumption from the improvement in well-being. It raises the prospect of decreasing pressures on consumption without a loss in the quality of life and hence of a sustainable economy." (O'Neill, 2006: 159). Indeed, the limited engagements with well-being in the 'traditional EJ' literature - the idea of economic well-being and the concern for health and well-being - both fit broadly within the hedonic tradition. In the former, well-being is seen as happiness, which in turn is explained as causally linked to one's ability to satisfy one's preference through having appropriate economic means for consumption. In the latter, well-being is understood as experiencing positive emotions or states of mind by virtue of good health. Of course, this post-hoc analysis must be tempered by the understanding that EJ scholarship never set out to formulate its justice claims in terms of well-being. Rather, its justice claims were grounded in the social contract. So when Bullard (1990) questioned the justice of where noxious environmental facilities were located, the injustice lay in their unequal distribution and particularly the fact that they were disproportionately located adjacent to poor black communities. Undoubtedly, the well-being of these communities was affected by this, but their well-being was in many senses secondary to the larger distributive inequality, and particularly the fact that this inequality could not be justified according to any accepted approach to justice. Quite the opposite, it ran directly counter to Rawls' 'maximin' principle.

Scholars developing the emerging capabilities EJ, by contrast, have formulated their justice claims in terms of ability to 'function'. As Schlosberg puts it in a recent intervention, "Being able to function is what is ethically significant, and injustice is found in the limitation of capabilities necessary for that functioning" (Schlosberg, 2012: 452). In framing justice in this way, scholars are more clearly framing well-being in eudaimonic terms than even Sen and Nussbaum do in the development of capabilities theory. For instance, Sen views happiness (which, confusingly, he sometimes calls 'subjective well-being') as one capability among many to be considered in assessing justice or injustice: "happiness is not the only thing we seek, or have reason to seek" (Sen, 2009: 277). So capabilities EJ is already pushing at the limits of capabilities theory's current engagement with well-being (Arneson, 2013). But it is eudaimonic in orientation, whereas traditional EJ is rather more ambivalent, but if anything has tended to implicitly understand wellbeing in hedonic terms. Yet, drawing on Holifield's (2004) case of how EJ was institutionalized into the US EPA's program to clean up hazardous waste sites, we might also reflect that though the US Government's strategies to bring EJ within a broader neoliberal paradigm were ultimately unsuccessful in totally 'normalizing' (or 'neutralizing') the EJ community, the attempt to do so was substantially aided by the fact the EJ movement never explicitly defined what it meant by well-being. 
Traditional EJ was always in danger of the co-opting influence of mainstream justice discourses, but where capabilities EJ has largely overcome this by more consciously (and conscientiously) defining justice, it seems that at present it is vulnerable to a similar process of co-option by mainstream well-being discourses. In setting out his capabilities approach (which on balance seems to have been more influential to EJ scholars than Nussbaum's), Sen deliberately leaves the conditions under which justice is achieved underspecified, and there is space within capabilities theory for well-being to be approached in hedonic terms, since the only guidelines it provides for justice is that people should be able to do things they have reason to value; to feel that their lives are valuable. Though capabilities EJ appears to consciously be adopting a eudaimonic conception of well-being, more work is required to clearly and carefully articulate this to circumvent attempts to co-opt it by emphasizing hedonic descriptors in assessing capabilities and functioning.

Despite its flaws, it was arguably the strength of the liberal social contract tradition which conferred on EJ a certain moral authority which was accepted by society more broadly, particularly as the movement developed in the USA. It gave scholars as scholar-activists a moral platform from which to speak out against injustices being experienced by others. But this position of moral authority is by no means secure for capabilities EJ, because with notions of well-being the ultimate goal of capabilities theory, even if we adopt the broader framing of community capabilities advocated by Schlosberg and Walker, it would seem particularly critical to have the community (or communities) suffering injustice politically mobilized to provide a moral basis for claims of injustice. A failure to mobilize, or indeed a more basic failure of claimants to articulate how their well-being is being circumscribed by a lack of capabilities, becomes much more theoretically problematic with capabilities EJ, since capabilities theory understands justice in only comparative terms, not transcendental ones. Whether or not it is practically problematic is harder to ascertain.

However, in the 'classic' local-scale EJ case of a poor black community living adjacent to a noxious environmental facility (discussed above), a Rawlsian framing of justice provides a clear account of both what the problem is (inequality, maldistribution of an environmental 'bad') and how it should be addressed (compensating benefits to the least advantaged). A capabilities framing of justice, by contrast, raises a series of questions which must be answered in order to establish the basis of the normative claim: What is the condition of the community in question? How do they feel that their well-being is impacted by the facility? What is the best functioning of the community in question? How is the functioning of the community affected by the facility? Likewise at the international scale, if we consider debates about climate justice, a Rawlsian framing of justice provides a clear rationale for action to protect those who are both least responsible and likely to be most severely affected. We think capabilities provides a much more theoretically attractive basis for taking action on climate change, including the kind of 'justice' actions essential for proper climate change adaptation (Schlosberg, 2012), but it also requires mobilizing both a complex academic vocabulary and a diverse affected community.

So the political mobilization of the 'affected community' is thus much more important to establish the normative validity of a capabilities-based claim of injustice than a social contractbased claim, where scholar-activists could speak on behalf of communities from the perspective 
of recognized normative positions. This renewed need to go back to the community as the claimants for justice could, on balance, be a positive thing for EJ scholars. However, it is accompanied by an increasing specificity in the 'justice' of EJ which could limit the political purchase of EJ arguments, particularly at scales greater than the local where consensus is much harder to achieve. Though it is outwith the remit of this paper, this suggests that some more refined thinking is required on the scalar implications of the way both justice and well-being are framed within EJ scholarship.

Geographers, of course, are well placed to contribute to a better understanding of how scale affects notions of well-being such as those introduced in this paper, which at present focus almost exclusively on the individual, personal scale. For instance, scholars could think through the implications of different scalar perspectives on the way well-being is framed, and develop ways to reduce the primacy of the individual in capabilities theory. In doing so, we hope they might also to develop new indicators of in/justice - ways of determining how just or unjust a policy, programme or existing socio-natural arrangement is - which build on the insights of both justice pluralism and capabilities theory. This will inevitably involve a process of mutual dialogue with normative and philosophical theory like that called for by Olson and Sayer (2009: 193), who argue that geography's command of the empirics of uneven development can "contribute to philosophical considerations of equality and wellbeing, just as a more thorough engagement with moral philosophy and with normative reasoning can improve the quality of our geographical work by sharpening our language and categories and exposing our assumptions to mutual critique".

EJ epitomises the tension at the heart of any radical normative project: its radical aspirations constantly come up against the constraints of what is politically possible to mainstream society. Indeed, this tension was in many senses the prompt which catalysed the recent shift to capabilities theory, which is more plural and more comparative, than Rawlsian justice ever was. But scholars must support the incipient capabilities EJ with a conscious and nuanced theorization of wellbeing, since if justice is achieved when people are able to live lives they consider worthwhile, then the way well-being is defined and the way it is protected from co-option will be fundamental to the kind of justice which a capabilities EJ ends up delivering.

\footnotetext{
${ }^{\mathrm{i}}$ In the hedonic psychological literature, happiness is defined in terms of the absence of negative affect. This is rather different from the way affect is understood in the substantial body of geographical scholarship on 'affective' or emotional geographies which uses the same term and generally understands affect as "a quality of life that is beyond cognition and always interpersonal. It is, moreover, inexpressible: unable to be brought into representation" (Pile, 2010: 8; see also Thein, 2005). Some boundary crossing work between geographical and psychological understandings of 'affect' would certainly be productive. For example examining the extent to which (geographical) affect and types of well-being are similar is an area ripe for further investigation. However, that is not the focus of this paper, and because of the potential for misunderstandings, we have avoided using the term affect in this paper.
} 


\section{References}

Adger WN. (2002) Inequality, environment, and planning. Environment and Planning A 34: 1716-1719.

Agyeman J, Bullard RD and Evans B (eds). (2003) Just Sustainabilities: Development in an Unequal World, Cambridge MA: MIT Press.

Albrecht SL. (1995) Equity and Justice in Environmental Decision Making: A Proposed Research Agenda. Society \& Natural Resources 8: 67-72.

Andrews GJ, Chen S and Myers S. (2014) The 'taking place' of health and wellbeing: towards non-representational theory. Social Science \& Medicine: 210-222.

Arneson RJ. (2013) From primary goods to capabilities to well-being. Critical Review of International Social and Political Philosophy 16: 179-195.

Atkinson S. (2013) Beyond Components of Wellbeing: The Effects of Relational and Situated Assemblage. Topoi 32: 137-144.

Atkinson S and Joyce KE. (2011) The place and practices of well-being in local governance. Environment and Planning C: Government and Policy 29: 133-148.

Ballet J, Koffi J-M and Pelenc J. (2013) Environment, justice and the capability approach. Ecological Economics 85: 28-34.

Barnett C. (2011) Geography and ethics: Justice unbound. Progress in Human Geography 35: 246-255.

Bina $\mathrm{O}$ and Vaz SG. (2011) Humans, environment and economies: from vicious relationships to virtuous responsibility. Ecological Economics 72: 170-178.

Blanchflower DG and Oswald AJ. (2008) Is well-being U-shaped over the life cycle? Social Science \& Medicine 66: 1733-1749.

Bourke L and Geldens PM. (2007) Subjective Well-Being and its Meaning for Young People in a Rural Australian Center. Social Indicators Research 82: 165-187.

Bullard RD. (1990) Dumping in Dixie: Race, Class, and Environmental Quality, Boulder (Colorado): Westview press.

Christopher JC. (1999) Situating Psychological Well-Being: Exploring the Cultural Roots of Its Theory and Research. Journal of Counseling \& Development 77: 141-152.

Cutter SL. (1995) Race, class and environmental justice. Progress in Human Geography 19: 111-122.

Debbané A-M and Keil R. (2004) Multiple Disconnections: Environmental Justice and Urban Water in Canada and South Africa. Space and Polity 8: 209-225.

Di Chiro G. (1996) Nature as Community: The Convergence of Environment and Social Justice. In: Cronon W (ed) Uncommon Ground: Rethinking the Human Place in Nature. New York: W. W. Norton \& Company, 298-320.

Diener E and Biswas-Diener R. (2008) The science of optimal happiness, Boston: Blackwell.

Diener E, Lucas R and Scollon CN. (2006) Beyond the hedonic treadmill: Revising the adaptation theory of well-being. American Psychologist 61: 305-314.

Diener E, Suh EM, Lucas RE and Smith HL. (1999) Subjective Well-Being: Three Decades of Progress. Psychological Bulletin 125: 276-302.

Dodds S. (1997) Towards a 'science of sustainability': Improving the way ecological economics understands human well-being. Ecological Economics 23: 95-111.

Ferraro E and Reid L. (2013) On sustainability and materiality: Homo faber, a new approach. Ecological Economics 96: 125-131.

Fleuret S and Atkinson S. (2007) Wellbeing, health and geography: A critical review and research agenda. New Zealand Geographer 63: 106-118.

Forsyth T. (2014) Climate justice is not just ice. Geoforum 54: 230-232. 
Fraser N. (1997) Justice Interruptus: Critical Reflections on the "Postsocialist" Condition, New York: Routledge.

Fraser N. (2000) Rethinking Recognition. New Left Review 3: 107-120.

Frey BS and Stutzer A. (2005) Happiness research: state and prospects. Review of Social Economy 63: 207-228.

Harvey D. (1996) Justice, Nature and the Geography of Difference, Cambridge MA: Blackwell Publishers.

Haughton G. (1999) Environmental Justice and the Sustainable City. Journal of Planning Education and Research 18: 233-243.

Holifield R. (2004) Neoliberalism and environmental justice in the United States environmental protection agency: Translating policy into managerial practice in hazardous waste remediation. Geoforum 35: 285-297.

Holifield R, Porter M and Walker G. (2009) Spaces of Environmental Justice: Frameworks for Critical Engagement. Antipode 41: 591-612.

Holland B. (2008) Justice and the Environment in Nussbaum's "Capabilities Approach": Why Sustainable Ecological Capacity Is a Meta-Capability. Political Research Quarterly 61: 319-332.

Holland B. (2014) Allocating the Earth: A Distributional Framework for Protecting Capabilities in Environmental Law and Policy, Oxford: Oxford University Press.

Honneth A. (2004) Recognition and Justice: Outline of a Plural Theory of Justice. Acta Sociologica 47: 351-364.

Huta V and Ryan RM. (2009) Pursuing Pleasure or Virtue: The Differential and Overlapping Well-Being Benefits of Hedonic and Eudaimonic Motives. Journal of Happiness Studies 11: 735-762.

Jaggar AM. (2006) Reasoning About Well-Being: Nussbaum's Methods of Justifying the Capabilities. The Journal of Political Philosophy 14: 301-322.

Kearns RA. (2014) The health in "life's infinite doings": A response to Andrews et al. Social Science \& Medicine 115: 147-149.

Kesebir P and Diener E. (2008) In Pursuit of Happiness: Empirical Answers to Philosophical Questions. Perspectives on Psychological Science 3: 117-125.

Layard R. (2005) Happiness Lessons from a New Science, London: Allen Lane-Penguin Books.

Linley PA, Maltby J, Wood AM, Osborne G and Hurling R. (2009) Measuring happiness: The higher order factor structure of subjective and psychological well-being measures. Personality and Individual Differences 47: 878-884.

Martin A. (2013) Global environmental in/justice, in practice: introduction. The Geographical Journal 179: 98-104.

Mathews G and Izquierdo C. (2009) Pursuits of happiness: well-being in Anthropological Perspective, Oxford: Berghahn Books.

Mohai P, Pellow DN and Roberts JT. (2009) Environmental Justice. Annual Review of Environment and Resources 34: 405-430.

Nussbaum MC. (2006) Frontiers of justice: disability, nationality, species membership, Cambridge MA: The Belknap Press.

O’Neill J. (2006) Citizenship, Well-Being and Sustainability: Epicurus or Aristotle? Analyse \& Kritik 28: 158-172.

O’Neill J. (2008) Happiness and the Good Life. Environmental Values 17: 125-144.

Olson E and Sayer A. (2009) Radical Geography and its Critical Standpoints: Embracing the Normative. Antipode 41: 180-198. 
Pavot W and Diener E. (1993) Review of the Satisfaction With Life Scale. Psychological Assessment 5: 164-172.

Pearce JR, Richardson EA, Mitchell RJ and Shortt NK. (2010) Environmental justice and health: the implications of the socio-spatial distribution of multiple environmental deprivation for health inequalities in the United Kingdom. Transactions of the Institute of British Geographers 35: 522-539.

Pile S. (2010) Emotions and affect in recent human geography. Transactions of the Institute of British Geographers 35: 5-20.

Rawls J. (1999) A Theory of Justice, Cambridge MA: Harvard University Press.

Ryan RM and Deci EL. (2001) On Happiness and Human Potentials: A Review of Research on Hedonic and Eudaimonic Well-Being. Annual Review of Psychology 52: 141-166.

Ryff CD, Singer B and Love GD. (2004) Positive health: connecting well-being with biology. Philosophical Transactions of the Royal Society B 359: 1383-1394.

Ryff CD and Singer BH. (2008) Know Thyself and Become What You Are: A Eudaimonic Approach to Psychological Well-Being. Journal of Happiness Studies 9: 13-39.

Sagoff M. (2008) The Economy of the Earth: Philosophy, Law, and the Environment, Cambridge: Cambridge University Press.

Schlosberg D. (2004) Reconceiving Environmental Justice: Global Movements And Political Theories. Environmental Politics 13: 517-540.

Schlosberg D. (2007) Defining Environmental Justice: Theories, Movements, and Nature, Oxford: Oxford University Press.

Schlosberg D. (2012) Climate Justice and Capabilities: A Framework for Adaptation Policy. Ethics \& International Affairs 26: 445-461.

Schlosberg D. (2013) Theorising environmental justice: the expanding sphere of a discourse. Environmental Politics 22: 37-55.

Schlosberg D and Carruthers D. (2010) Indigenous Struggles, Environmental Justice, and Community Capabilities. Global Environmental Politics 10: 12-35.

Schwanen T and Atkinson S. (2015) Geographies of wellbeing: an introduction. The Geographical Journal 181: 98-101.

Sen A. (1993) Capability and Well-Being. In: Sen A and Nussbaum MC (eds) The Quality of Life. Oxford: Clarendon Press, 30-54.

Sen A. (2009) The Idea of Justice, London: Allen Lane.

Sen A and Nussbaum MC (eds). (1993) The Quality of Life, Oxford: Clarendon Press.

Soper K. (2007) Re-thinking the 'Good Life': The citizenship dimension of consumer disaffection with consumerism. Journal of Consumer Culture 7: 205-229.

Swyngedouw E and Heynen NC. (2003) Urban Political Ecology, Justice and the Politics of Scale. Antipode 35: 898-918.

Sze J and London JK. (2008) Environmental Justice at the Crossroads. Sociology Compass 2: $1331-1354$.

Thein D. (2005) After or beyond feeling? A consideration of affect and emotion in geography. Area 37: 450-454.

Tiberius V. (2004) Cultural differences and philosophical accounts of well-being. Journal of Happiness Studies 5: 293-314.

Tucker I. (2011) Psychology as Space: Embodied Relationality. Social and Personality Psychology Compass 5: 231-238.

Walker G. (2009a) Beyond Distribution and Proximity: Exploring the Multiple Spatialities of Environmental Justice. Antipode 41: 614-636.

Walker G. (2009b) Environmental Justice and Normative Thinking. Antipode 41: 203-205. 
Walker G. (2012) Environmental Justice: Concepts, evidence and politics, London: Routledge.

Walker G and Bulkeley H. (2006) Geographies of environmental justice. Geoforum 37: 655659.

Walker G and Day R. (2012) Fuel poverty as injustice: Integrating distribution, recognition and procedure in the struggle for affordable warmth. Energy Policy 49: 69-75.

Whitehead M. (2009) The Wood for the Trees: Ordinary Environmental Injustice and the Everyday Right to Urban Nature. International Journal of Urban and Regional Research 33: 662-681.

Young IM. (1990) Justice and the Politics of Difference, Princeton NJ: Princeton University Press. 